\title{
Contrastive Analysis in China: Today and Yesterday
}

\author{
Hongwei Jia \\ Department of Chinese Minority Languages and Literature, Minzu University of China, Beijing, 100081, China \\ Email: george008023@yahoo.com.cn \\ Jiafeng Tian \\ Purchasing Department, Beijing Techwin Electric Co., Ltd, No.8 Boxing Yi Road, Beijing Economic and Technological \\ Development Zone, Beijing, 100000, China \\ Email: 461926566@qq.com
}

\begin{abstract}
It is widely believed among linguists in China and even in the world at large that contrastive analysis (also contrastive linguistics) was borrowed from the Western linguistics by the hand of Ma Jianzhong, a Chinese linguist in the late Qing Dynasty and author of China's first grammar book Ma's Grammar Book of the Chinese Language (1898), and that the starting point of contrastive analysis in Chinese philology is 1898, the year when Ma's Grammar book of the Chinese Language was officially published. However, this remark is inconsistent with the historical fact and aichives on the development of contrastive analysis in China. Through the literatures available on Buddhist translation studies, traditional Chinese rhetoric and Chinese grammar by Western missionaries, we find that the development of contrastive analysis in China has three clues: Buddhist translation practice, the earliest source which can trace back to the period of Three Kingdoms (220 A.D-280 A.D.), Western Missionary Chinese grammar books of which Wonder of Western Writing (1605) is one of the earliest grammar books involving remarks on contrastive analysis between Chinese and western tongues, and traditional Chinese rhetoric literatures in which contrastive analysis was found to come into being during the Latter Jin Dynasty.
\end{abstract}

Index Terms - contrastive analysis, sources of Chinese contrastive analysis, status-quo, history

\section{INTRODUCTORY REMARKS}

Since 1957, when Robert Lado put in print Linguistics across Cultures (1957), contrastive analysis has popped into a popular topic among scholars, though Benjamin Lee Whorf proposed the term of "contrastive analysis" in 1941 (Whorf, 1941, p.240). In China, contrastive analysis was paid attention to since 1980s, and reached its peak at the turn of the century.

It is widely agreed among Chinese scholars that contrastive analysis was introduced from western scholars. In Contrastive Linguistics: Historical and Philosophical Survey (2006), Pan Wenguo \& Tan Huimin believe that Ma Jianzhong, author of Ma Shi Wentong (Ma's Grammar Book of the Chinese Language, 1898), imported this practice in compiling the first Chinese grammar book (the first by Chinese scholar), with reference to western gelangma (actually a transliteration of the French word Grammaire introduced by Ma), which was regarded the beginning of Chinese contrastive analysis (Pan \&Tan, 2006, p.82-86), and that contrastive analysis in the West started with German linguist Humboldt in "On the Comparative Study of Language and Its Relation to the Different Periods of Language Development" (Humboldt, 1820, p.1). But I wonder in deed if it is as what Pan \& Tan dealt with in their book.

In the West, ancient Greek is the source of the western languages and cultures in that "the Latin is a composition of the Greek and of the ancient Tuscan languages" (Smith, 1985, p.193), and Latin grammar was also established, based on Greek grammar system, in which process contrastive analysis must have been used and did come into being, the origin of today's contrastive analysis. Since then on, this practice has ever been used to deal with linguistic issues by scholars from all schools of all times. Before Humboldt, Adam Smith took comparison as one of three means (comparison, generalization and abstraction) to elucidate his views on the first formation of languages in "Considerations Concerning the First Formation of Languages" (1761), so Humboldt is not the first western scholar who ever talked about this practice in linguistic matters.

What about the origin and its development of contrastive analysis in China? Is it as what Pan and other scholars who hold the same view that contrastive analysis started with Ma Jianzhong (1898)? This paper aims to give a historical outline of contrastive analysis in China, focusing on what contrastive analysis is, when this practice got started, what fields it was ever used, etc.

\section{How IT WAS DEFINED In CHINA}

Before we explore the origin of contrastive analysis in China, we need necessarily to find out what contrastive 
analysis and its nature are, which forms the prerequisite of our further exploration in this paper. For the sake of convenience, we, in this paper, take only the definitions given by Chinese linguists.

Contrastive analysis is also called contrastive studies or contrastive linguistics; they are co-referents to the same subfield of linguistics and served frequently as equivalents to each other in a general sense, and contrastive linguistics is generally considered much more formal. However, for some linguists, the three terms bear their distinctions. As to the distinctions between contrastive analysis and contrastive linguistics, Yang Zijian (1937-2009), the late professor from China Ocean University, believes that "contrastive analysis, the earliest referent derived from comparative philology, is a method of linguistic analysis, focusing on applied contrastive analysis while contrastive studies covers theoretical and applied linguistic analysis" (Yang, 1999, p.72; Yang, 2004, p.40, my translation).

As to what contrastive analysis or contrastive linguistics is, $\mathrm{Xu}$ Yulong is the first Chinese scholar to give this subject a definition as below:

Contrastive analysis is more often used for applied contrastive studies, especially as a method in foreign language teaching, thus often associated with contrastive analysis hypothesis ${ }^{l}$. (Xu, 1992/2002, p.444)

This definition originally put forth in A General Introduction to Contrastive Linguistics (Xu, 1992), is language-teaching oriented and given in a narrow sense. In this paper, we take contrastive analysis in a general sense, which equals contrastive linguistics defined as:

Contrastive linguistics (analysis) is a branch of linguistics which aims at a systematic synchronic description of two (or more than two) languages in order to determine the similarities and differences between them and find out the implications of such similarities and differences for language-related activities. (Xu, 1992(b), p.12; Xu, 2002, p.445)

In the definition above, we can find the following features: Firstly, it is a branch of linguistics; secondly, it focuses on the synchronic study of two or more languages; thirdly, it aims to discover the differences and similarities, especially the differences, by the means of description; fourthly, its findings will be applied to related fields.

Grounded on the definitions available, Yang Zijian, from the perspective of contrastive study of English and Chinese, revised them as the following:

Contrastive linguistics between English and Chinese is a subfield of linguistics, with theoretical linguistics and applied linguistics in nature, which aims at a synchronic and diachronic contrastive study between English and Chinese in order to describe and explicate the differences and similarities between them and apply the findings to language studies and other related fields. (Yang, 1994, p.14-15; my translation)

In this definition, Yang stresses on its nature of theoretical and applied linguistics, its focuses on discovering their differences and similarities, and on describing and explicating them, which are the advances of this definition. Pan Wenguo \& Tan Huiying, based on this definition, gives their revised version as follows:

Contrastive linguistics is a subfield of linguistics under the guidance of linguistic philosophy, focusing on all the levels of theoretical and applied linguistics, which aims at contrastive study of two or more languages or dialects in order to describe their differences and similarities, especially the differences, and explicate both of them in terms of the relationship between human languages and their spiritual activities for driving the building and development of general linguistics, promoting the understanding of and communicating between cultures and civilizations, and reaching the goal of people all over the world living in harmony. (Pan \& Tan, 2006, p.252-253; my translation)

In Pan and Tan's definition, they make the following four improvements: firstly, it is put in the guidance of linguistic philosophy; secondly, it can also be used to study dialects besides individual languages; thirdly, it claims to explicates the differences and similarities between languages or dialects in terms of the relationships between human languages and their spiritual activities; fourthly, it calls for new aims of building and developing the subject, promoting interlingual communication and understandings, and reaching the goal of world in harmony except for language teaching and other language-related applications.

From the above definitions, we can conclude that the objects of CA are two or more languages or dialects, its methods are synchronic or both of synchronic and diachronic contrast or comparison, its task is find out the differences and similarities between languages or dialects, and its aim is to describe and explicate their differences and similarities for further use in other areas. However, comparative linguistics focuses on comparing languages in order to trace their phylogenetic relationships in order that the putative parent language from which kindred languages are thought to have descended could be reconstructed, and the materials taken for comparison consist in the main of individual sounds and words.

\section{Aims AND New DEVElopments of CA AS A Discipline}

For CA, the essential prerequisite is to grasp the basic properties or say heterological elements of two or more languages in question, as formal issues in languages are in nature formal expressions made of the given linguistic qualities. If the basic properties or heterological elements of two languages are found, the implications of their differences and similarities could be determined for further use in other areas.

\footnotetext{
${ }^{1}$ Contrastive analysis hypothesis is an assumption that we can predict and describe the patterns of L2 that will cause difficulty in learning and those that will not cause difficulty through contrastive analysis of L1 and L2. Its strong version claims that CA has the capacity of predicting errors, while its weak version suggests that it is only tenable in diagnostic function. (Xu, 2002, p.444)
} 
As to the aims of CA, Gerhard Nickel believes that contrastive linguistics for the most part compares languages with the quite utilitarian aim of improving the methods and results of language teaching, (but) it is not merely relevant for foreign-language teaching, it can (also) make useful contributions to machine translation and linguistic typology (Nickel, 1971, p.1-2). Christopher N. Candlin also believes in the preface for Contrastive Linguistics (James, 1980) that there was always more to contrastive analysis than making claims about learner difficulty (in that) contrastive analysis has had much to offer to translation theory, the description of particular languages, language typology and the study of language universals. From the quotations above, we learned that CA started with language teaching, and then extended into the areas of translation studies, linguistic typology and even dictionary compiling, focusing on the application of CA theory, which promotes the establishment and development of CA as a separate discipline.

As CA may be conducted intralingually or interlingually, on a synchronic or diachronic basis, four types of comparison may be distinguished: synchronic intralingual comparison, diachronic intralingual comparison, synchronic interlingual comparison and diachronic interlingual comparisom (Xu, 1992b, p.12-13; Ke, 1999, p.6-9), which could be illustrated in the following diagram:

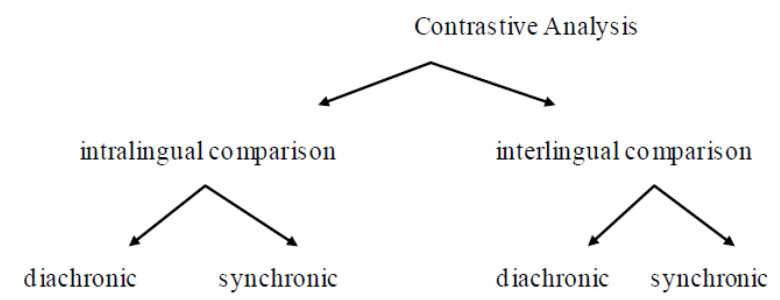

Diachronic intralingual comparison refers to the comparison of constituents on the levels of sound (phonetic and phonological), words (lexical), structure (grammatical) and meaning within a language through history to determine what changes of the given constituents occurred, which is in the area of philology, mainly adopted by linguists in linguistic history, etymology, etc. while synchronic intralingual comparison refers to the comparison of constituents on the same levels within a particular language during a given period.

Diachronic interlingual comparison is so-called comparative historical linguistics, which mainly focused on comparing historically related forms (especially sound) in different languages to reconstruct the proto-language while synchronic interlingual comparison is developed lately and most complicated, which focuses on comparing two or more languages or dialects to determine the differences and similarities and to find out the implications of the differences and similarities for language universals, linguistic typology, language teaching and other language-related areas as mentioned above.

In terms of the purposes of CA researchers, we may classify it into theoretical contrastive linguistics and applied contrastive linguistics, the former emphasizing on giving an exhaustive account of the differences and similarities between two or more languages or dialects, providing adequate models and theoretical frameworks for their comparison, and determining how and what elements are comparable, establishing basic notions as congruence, similarity and equivalence between the forms of different languages, and arranging theoretical findings and models for applied CA research while the latter taking as its objective the application of theoretical findings to compare two or more languages or dialects for practical purposes, for instance, language teaching and learning, translation studies, bilingual dictionary lexicography, etc. Furthermore, theoretical CA can be divided into general and particular CA theoretical studies while applied CA into general and particular CA applied studies, as the following diagram shows:

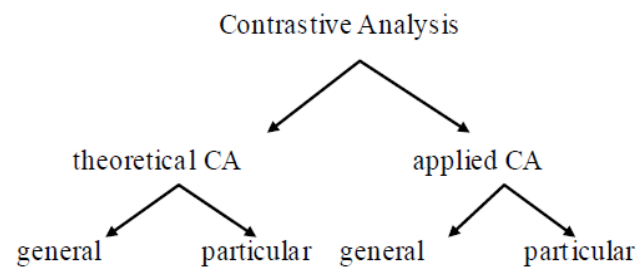

In view of the areas studied, CA can be broken into macro contrastive analysis and micro contrastive analysis, the former representing a broader perspective of linguistic analysis, with the goal of determining what elements to be compared and of comparing how people use language to communicate with each other, equaling to some extent theoretical CA, while the latter being the classic CA, with the goal of comparing the universal as well as particular properties of languages on the levels of phonetics, phonology, lexis, grammar and meaning. Besides what mentioned about the levels of macro CA, textual and pragmatic levels are also considered, with the popularity of translation studies.

The status quo and general development of modern CA in China have been dealt with, and we, through literatures on linguistics since 1898 when Ma Jianzhong put in print his book on Chinese grammar and 1912 when the first book on linguistics was published, find that the CA practice in China was introduced from the West first by Ma Jianzhong after 
he had finished his study in France and then by way of mainly Japanese translations of general linguistics and historical linguistics of European linguists, starting with Rudiments of the Chinese Spoken Language ${ }^{2}$ (1912) by Hu Yilu, an ever student in the linguistics program at the then Tokyo Imperial University, followed by Chinese translation of An Teng Zheng Ci's [安騰正次] A General Introduction to Linguistics ${ }^{3}$ (1927) by Wang Gulu, a Chinese linguist in 1930s, and other translations of linguistic literatures from various sources, among which Yu Yan Xue Shi [History of Linguistics] (1943) is a specific book focusing on importing linguistic methods of historical and comparative philology.

However, before the introduction of modern CA, there existed CA practice in Chinese philology, but when CA came into being in China has been open to debate.

\section{When does Contrastive AnAlysis COME INTO BiRTH IN CHINA?}

Chinese is a unique language in terms of linguistic typology, and Chinese characters are also regarded as a system with the longest history, both of which are considered as the transmission medium of Chinese cultures, the source and foundation of Chinese culture circle in Asia. In the development of the Chinese language, two forces of foreign cultures ever took their parts, one of which is Buddhism filtering into China in the $1^{\text {st }}$ century, coming with its influences on Chinese sound studies and Chinese poetic parody; the other is Christianity entering into China with modern Western science and technology, with its impacts on the reformation of the Chinese system and linguistic methodology.

In translating the religious sutras and canons, contrastive analysis got into birth. In the process of compiling Chinese learning books for missionaries and of learning Chinese for sake of spreading their religious doctrines, contrastive analysis was used to the best. Besides the influences of the two forces, there is another force within traditional Chinese rhetoric studies, forming its own style of contrastive analysis.

\section{A. Contrastive Analysis Derived from Buddhist Translation}

It is universally agreed for the time that Buddhism filtered into China in the period of the Latter Han Dynasty ${ }^{4}$ (around the $1^{\text {st }}$ century) and the translation of Buddhist sutras started almost 100 years later. In the process of translating Buddhist sutras, translators observed the differences between Sanskrit and Chinese, as Zhi Qian ${ }^{5}$ (Lokaksema) in the period of Three Kingdoms (220 A.D-280 A.D.) tells in Preface to Dharma Pãda (230 A.D.) as follows:

“天竺言語與漢異音雲。其書爲天書語爲天語。名物不同傳實不易。”(支謙 $230: 5 b-c$ )

"Sanskrit differs from Chinese in sound; Sutras in Sanskrit are books from Heaven (devalipi), and Sanskrit sounds are sounds from Heaven. Names and objects in Sanskrit are all different from those in Chinese, so to render them is not an easy job" (Zhi, 230, p.5b-c; my translation).

In the quotation above, the differences between Sanskrit and Chinese are concluded from the contrastive analysis in the Buddhist translating process, so the quoted lines are not only an evidence for translation practice summary but a record of contrastive analysis in Buddhist translation. Between these lines quoted above, the differences on the levels of sound and naming was known by means of CA, and was called for translators' attention.

As to contrastive analysis in Buddhist translation, we can get further evidence from Tao An's summary of translation practice from the years 220-589 A.D. in Preface to Heart Sutra Translation in Compilation of Notes on the Translation of the Tripitaka (vol.8), in which Tao An (312-385 A.D.) proposed in terms of stylistic equivalence in translation his Theory of Five Losses as below:

“五失本、三不易”論, 即：“譯胡爲秦, 有五失本也：一者，胡語盡倒，而使從秦，一失本也。二者，胡經向 質, 秦人好文, 傳可眾心, 非文不合, 斯二失本也。三者, 胡經委悉, 至於歎詠, 叮嚀反復, 或三或四, 不嫌 其煩, 而今裁斥, 三失本也。四者, 胡有義說, 正似亂辭, 尋說向語, 文無以異, 或千五百, 㺫而不存, 四失 本也。五者, 事已全成, 將更傍及, 反騰前辭, 已乃後說, 而悉除此, 五失本也。”（道安, 摩訶缽羅若波羅密 經鈔序，《出三藏記集》卷 8 ; 參見周儀, 1998, p.6)

"In translating sutras from Sanskrit and other languages into Chinese, there occur Five Losses of forms: The inverted order in Sanskrit and other languages used in sutras should be rendered into Chinese word order, which is called the First Loss; The style of sutras is simple, but Chinese readers love adorned writings, so to meet Chinese readers' taste, the translation of sutras should be embellished, which is considered as the Second Loss; Repetitiveness preferred in Sutra bodies, especially in Panegyrics should be eliminated in Chinese translation, which is thought as the Third Loss; A texte with repetitive content of words ranging from 500 to 1000 (a text in form of summary), following each commentaire, should be eliminated, which is regarded as the Fourth Loss; The recapitulative lines about the previous section in the new introductory section should be eliminated, which is the Fifth Loss. " (Tao, Preface to Heart Sutra Translation; c.f. Zhou, 1999, p.6; my translation)

\footnotetext{
${ }^{2} \mathrm{Hu}$ Yilu in the book introduced into China linguistic methodology of "historical and comparative treatment of language, and science of principle" (1912, p.100), and called for the adoption of these methods in the study of the Chinese language.

${ }^{3}$ In this book, the theory and linguistic methodology were borrowed from European linguists and used to study Japanese. This book was ever used as the course book of linguistics in Taiwan Imperial University when 安騰, the author of the book, gave lectures of linguistics in Taiwan.

${ }^{4}$ Han Dynasty in Chinese history ranges in time from 202 B.C to 220 A.D., consisted of the Former Han Dynasty (202 B.C -23 A.D.) with its capital in today's Xi'an, the capital city of present Shan'xi province, and the Latter Han Dynasty (25 A.D.-220 A.D.) with its capital in today's Luo Yang, a city in the northwest of present Henan Province.

${ }^{5}$ Zhi Qian is his Chinese Buddhist name, as to when he was born and died was unknown.
} 
From the five differences mentioned in this quoted paragraph, we learned that during the years 220-589 A.D in China, contrastive analysis was adopted to analyze and compare the stylistic parameters of two or more languages on the textual level as the one popular in the world academic circle today.

And these methods used in Buddhist translation were borrowed by missionaries from all parts of the world to translate Christ scriptures in the late Ming Dynasty (c.f. Xu, 2008, p.20), which shows the values of contrastive analysis in religious translation. In addition to Christ scripture translation practice, translation practice of western science and technology works in the Late Ming Dynasty and the early Qing Dynasty also adopted the findings of contrastive analysis in translating Buddhist sutras, which can be seen in the Translator's Remarks of the translated version of Evolution and Ethics (1905) as below:

“譯文取明深義，故詞句之間，時有顛倒附益，不斤斤計較於字比句次,而意義不倍本文。.....西文句中名物 詞, 後乃遙接前文, 足意成句。故西文句法, 少則二、三字, 多者數十百言。”（嚴複 《天演論》譯例言）

"This translation is done, based on sense, not on the arrangement of words and sentences of the source text, so inversions and additions sometimes occur between the lines, but its content is not far from the source text. ... Words for names and objects in English sentences are connected and co-referred contextually, and a sentence is complete when a thorough thought is expressed, so an English sentence ranges from two or three words to several dozens of words. " (Yan, Remarks on Translation of On Evolution and Ethics, 1905)

Based on the summaries of translation practice, it is safe to suppose that contrastive analysis comes with Buddhist translation practice since the Latter Han Dynasty, and it was developed into linguistic theory to guide and direct the later Buddhist and Christ scripture translation practice, and even the translation of Western science and technology works, with the goal of producing high-quality translations. So we assert that contrastive analysis budding in ancient China has run through the embryonic stage into its maturity in the field of translation practice.

In addition to the contributions of contrastive analysis to religious translation, contrastive analysis was also adopted in making Chinese phonological system under the influence of the introduction of Sanskrit linguistic studies coming with Buddhist sutras. As to the details about Chinese phonological system, please refer to Chapter 5 of A Short History of Linguistics by Robins (2001, p.124-125).

In terms of its nature, contrastive analysis derived from translation practice in ancient China is performed interlingually and synchronically, which is evidently shown in the quotations above.

\section{B. Contrastive Analysis Derived from Missionaries' Grammar Writing}

Missionaries from all corners of the world came to China in the Ming Dynasty. To facilitate their religious missions and Chinese learning as the means of spreading Christian doctrines, they constructed Chinese-learning books by imitating Latin Grammar and comparing Chinese with their mother tongues on the levels of sound, structure and meaning, especially of sound.

The first known book of this sort is Wonder of Western Writing (1605) by Italian Missionary Matteo Ricci (1551-1610), which was composed of three articles on Catholic doctrines in the form of Chinese Romanization. Through systematic comparison, Matteo Ricci with the help of his fellow missionaries constructed the first reformation of Chinese Romanization, the foundation of Chinese pinyin system today, which is illustrated as the following table:

\begin{tabular}{|l|l|l|l|l|l|}
\hline Ricci System & Chinese Pinyin & Ricci System & Chinese Pinyin & Ricci System & Chinese Pinyin \\
\hline /su/ & /si/ & /hu/ & /fu/ & /o/ & /ong/ \\
\hline$/$ /shi/ & /xi/ & /yu/ & /you/ & /r/ & /l/ \\
\hline$/$ ti/ & /qi/ & $/ \mathrm{n} /$ & /ing,ang,eng,ong/ & & \\
\hline$/$ tsu/ & $/ \mathrm{e} /$ & /ei/ & & \\
\hline
\end{tabular}

In this system, /ti/ is read as /qi/ meaning "seven" (七) in Chinese, and /n/ represents nasals as ing, ang, eng, ong in the current Chinese Pinyin system. Even now this system is also used among Chinese overseas.

Based on Ricci's system of Chinese Romanization, Belgian Jesuit Nicolas Trigault (1577-1628) constructed traditional Chinese phonology in An Audio-visual Aid to Western Scholars or Xiru Ermu Zi (1626). Compared with Ricci's Italian-like transcription of Chinese characters, Trigault also referring to the pronunciation of European languages produced a quite Chinese-oriented transcription, which exerted much more impact upon the cognition of Chinese among missionaries and upon the development of traditional Chinese phonology.

Through comparing the structure of Chinese and European languages, Italian Jesuit Marinus Martini (1614-1661) constructed in Latin Grammatica Sinica (1653) which is one of the best-preserved Chinese grammar books written in Western languages, and may probably be the first intact Chinese grammar book.

Spanish missionary Franciso Varo (1627-1687) turned to study Chinese structure and sounds by comparing Chinese (an official speech based on Nanking dialect) with his mother tongue Castilian and French, and produced in Latin Arte de la Lengua Mandarina (1703) which is the first published Chinese grammar book worldwide.

Twenty years later, French Jesuit Joseph Henri Marie de Prémare (1666-1736) finished Notitia Linguae Sinicae (1728) which covered Chinese classic literatures, dictionaries, Chinese characters and sounds, and called for immersing the rules in thousands of Chinese grammar examples. It is believed among missionary Chinese grammar researchers that Prémare (1728) is the first to distinguish the spoken Chinese and the written Chinese (c.f. Lunbaek, 1991, p.180) on 
stylistic features and grammatical features through elucidating Chinese particles and their grammar rules. Prémare through comparison with European languages believed Chinese has no grammar besides a few grammar terms such as "full words", those capable of standing alone and bearing in individual lexical glosses, which are further divided into "living words" and "dead words", and "empty words" serving grammatical purposes within sentences containing full words but scarcely having a stable meaning in isolation (c.f. Robins, 2001, p.122). It is through Prémare that these terms have been passed into general linguistics. His analysis of Chinese in Prémare (1728) produced much influences among missionary Chinese scholars, among which Jean Pierre Abel Remusat (1788-1832) put in print Les élémens de la grammaire chinoise (1822), just to mention a few of them.

From the above evidences, we can see that contrastive analysis was adopted in analyzing Chinese in the areas of sound, structure and stylistic features and in writing "Chinese textbooks" in the early $17^{\text {th }}$ century China, which should be regarded the earliest contrastive analysis in the areas of language teaching and textbook writing in order to improve the learning performances among western missionaries. In terms of its nature in the $17^{\text {th }}$ century, contrastive analysis was conducted interlingually and synchronically as it was conducted in religious translation.

\section{Contrastive Analysis Derived from Traditional Chinese Rhetoric Studies}

However, in traditional Chinese philology, there also existed contrastive analysis, especially in the works of traditional Chinese rhetoric.

Zhi Yu (?-311A.D.), a man of letters in the Latter Jin Dynasty ${ }^{6}$, compared Chinese poetic styles in terms of traditional Chinese rhetoric in the book Wen Zhang Liu Bie Lun (Essay on the Origin of Literary Genres) (c.f. Yuan \& Zong, 1998, p.61) in which he traced the history of Chinese poetic genres, distinguished eleven poetic genres, and gave his comments on their roles respectively.

Followed by Liu Xie's Ti Xing (Of Genre and Character) in Wen Xin Diao Long (The Literary Mind and the Carving of Dragons, 501-502) on how to compose elegant Chinese writings, Liu Xie (around 465-520 A.D.) in this work made a contrastive analysis of writings by the authors of different characters, which touched on the relations between literary styles and writers' personality for the first time (c.f. Yuan \& Zong, 1998, p.74).

Li Zhiji (661-721) in Tang Dynasty, through contrastive analyses of history works in Shi Tong (Aspects of Historiography, 708), made a generalization and conclusion for the historiographical works before Tang Dynasty and discussed the theories and methods of historiography writing (c.f. Yuan \& Zong, 1998, p.96).

Chen Kui (1128-1203) in Song Dynasty made a breakthrough of contrastive analysis adopted by the three pioneers above. In his literary and rhetoric work Wen Ze (Theory of Writing), he conducted contrastive analyses of works of different times diachronically, of works of contemporary writers synchronically, of works of different genres and of different paragraphs of a same singe work (c.f. Yuan \& Zong, 1998, p.153-166). Since then on, contrastive analysis developed rapidly and reached its peak among the philologists in Qing Dynasty phonology researches.

As to the nature of contrastive analysis adopted by Chinese native scholars through history, it is mainly used in intralingual researches in the areas of literary styles and discourse analysis, and the theory and methods of writing. Contrastive analysis in the first three pioneers is more diachronic than synchronic while contrastive analysis in Chen Kui is both diachronic and synchronic, the first usage of both of them in a single philological work in Chinese history.

\section{Conclusion}

Through the analyses above, we can conclude that contrastive analysis derived from translation practice is based on the cultural barriers and linguistic differences to look for the commensurability between two languages for transmitting the thoughts and meaning from the source texts into the target texts, that contrastive analysis in missionary Chinese grammar books aims at finding a short cut in learning Chinese to achieve the best performance within the shortest time, which is the earliest form of current applied contrastive linguistics, and that intralingual contrastive analysis aims at making sense better, improving writing rules and rhetoric skills, developing stylistic norms, and generalizing grammar rules to lay a foundation for Chinese philology.

Contrastive analysis in the above fields came from the practices of religious and science translation, missionary grammar book writing and Chinese rhetoric researches and was developed into current theories of CA, following the law of "practice-theory- the integration of theory with practice", so the history of contrastive analysis in China is incomplete without the contrastive analysis in translation practice and missionary grammar book writing.

Additionally, Xun Gu (exegetics) in Chinese philology also involves contrastive analysis when scholars searched through literatures to explain the given words in ancient texts. This tradition can trace back to Han Dynasty, almost the same period as the contrastive analysis in Buddhist translation practice.

\section{CONCluding REMARKS}

The history of contrastive analysis in China starts both "intralingual CA" and "interlingual CA" from the Latter Han Dynasty to the early of Qing Dynasty, and follows the law of practice-theory-the integration of theory with practice. By the historic features and characters of contrastive analysis in China, the history of contrastive analysis in China can be

\footnotetext{
${ }^{6}$ It is also called West Jin in terms of its capital location.
} 
distinguished into the period of classic CA and of modern CA.

Classic CA starts with Buddhist translation practice and exegetics of Chinese philology in the Latter Han Dynasty, going through traditional rhetoric in the Latter Jin Dynasty and missionary grammar book writing in the late Ming Dynasty to the early Qing Dynasty. For details of classic CA, refer to 4.4 in this paper.

Modern CA starts with Ma's Grammar Book of the Chinese Language (1898), going through the stage of CA practice in language teaching (1898-1977) to the stage of CA theoretical development (1978-2010). The turning point from CA practice in language teaching to CA theoretical development is the lecture titled On the Exemplification of Contrastive Analysis in Chinese-English Grammar (Lv, 1977) which was developed and published with the title of Study Grammar through Contrasting (1977) in Journal of Language Teaching and Research. Since then on, Modern CA turned to the exploration of CA theory and the establishment of CA as a separate discipline. So far, modern CA has extended from the fields of phonetics, phonology, morphology, semantics, pragmatics, discourse analysis, etc. into the areas of bilingual lexicography, translation studies (descriptive translation studies, machine translation, translation process, etc.), textbook writing of Chinese as a foreign language, building of bilingual corpus, teaching of Chinese as a foreign language, etc.

\section{REFERENCES}

[1] An Teng Zheng Ci [安騰正次].(1927). A General Introduction to Linguistics. Tokyo: Waseda University Press.

[2] Hu, Yilu. (1912). Guo Yu Xue Cao Chuang [Rudiments of the Chinese Spoken Language]. Shanghai: Commerce Press.

[3] Humboldt, Wilhelm Von. (1820). On the Comparative Study of Language and Its Relation to the Different Periods of Language Development, in T. Harden and D. Farrelly (1997.). Essays on Language. Frankfurt am Main: lang, pp.1-22.

[4] James, Carl. (1980). Contrastive Analysis. Harlow Essex: Longman Group UK Ltd [See also: Qingdao: Qingdao Publishing House, 2005].

[5] Jia Hongwei. (2010). A Review of Contrastive Linguistics: Historical and Philosophical Survey. Journal of Russian Language and Literature Research, pp. 63-66.

[6] Ke Ping. (1999). Contrastive Linguistics. Nanking: Nanking Normal University Press.

[7] Lado, R. (1957). Linguistics across Cultures. Ann Arbor: UMP.

[8] Lin Zhuyu. (1943). Yu Yan Xue Shi [History of Linguistics]. Shanghai: World Publishing House.

[9] Lundbaek, Knud.(1991). Joseph de Prémare (1666-1736), S. J. -Chinese Philology and Figurism. Aarhus: Aarhus University Press.

[10] Lv Shuxing. (1977). "Study Grammar through Contrasting", in Language Teaching and Research (vol.2, pp.1-16). Beijing: Beijing Institute of Language.

[11] Ma Jianzhong. (1898-1899). Ma Shi Wentong [Ma's Grammar Book of the Chinese Language]. 2 vols. Beijing (see also. Beijing: Commercial Press, 1983.) .

[12] Nickel, G. (1971). Contrastive Linguistics and Foreign language Teaching, in Nickle, G (ed.), Papers in Contrastive Linguistics. Cambridge: Cambridge University Press, pp. 1-16.

[13] Pan Wenguo \& Tan Huimin. (2006). Contrastive Linguistics: Historical and Philosophical Survey. Shanghai: Shanghai Educational Publishing House.

[14] Robins, R. H. (2001). A Short History of Linguistics. Beijing: Foreign Language Teaching and Research Press.

[15] Smith, Adam. (1761). 'Considerations Concerning the First Formation of Languages, and the Different Genius of Original and Compounded Languages', in T. Beckett \& P. A. Dehondt (ed.), The Philological Miscellany. vol.I, pp.440-479.

[16] Smith, Adam. (1985). Lectures on Belles Lettres. J. C. Bryce (Ed). Indianapolis: Liberty Fund, pp.180-197.

[17] Tao An. Preface to Heart Sutra Translation, in Compilation of Notes on the Translation of the Tripitaka, vol.8.

[18] Whorf, B.L. (1941). Language and Logic, in John, b. Carrol (ed), Language, Thought, and Reality: Selected Writings of Benjamin Lee Whorf. Cambridge, Massachusetts: The MIT Press, pp. 233-245.

[19] Xu Guangtai. (2008). A Survey on the Introduction and Translation of Key Category Terms into China in the Late Ming Dynasty, Yao, Xiaoping (ed.), Hai Wai Han Yu Tan Suo400 Nian Guan Kui [400 Years of Overseas Chinese Study]. Beijing: Foreign Language Teaching and Research Press, pp. 10-46.

[20] Xu Yulong. (1992a). A General Course to Contrastive Linguistics. Shanghai: Shanghai Education Publishing House, pp. 4.

[21] Xu Yulong. (1992b). Definition and Classification of Contrastive Linguistics. Journal of Foreign Languages, vol.4, pp. 12-17.

[22] Xu Yulong. (2002). Contrastive Linguistics. Shanghai: Shanghai Education Publishing House.

[23] Yan Fu. (1905). Remarks on Translation of On Evolution and Ethics, in Yan, Fu (Tr.), On Evolution and Ethics. Shanghai: Commerce Press.

[24] Yang Zijian. (1994). A Few Remarks on Contrastive Study between English and Chinese and Translation Theory Building, in Liu Chongde (ed.), Contrastive Studies of English and Chinese. Changsha: Hu Nan Science and Technology Press, pp. 12-25.

[25] Yang Zijian. (1999). Some Issues in Contrastive Linguistics. China Ocean University Journal, vol.2, pp.72-77.[also Wang Juquan \& Zheng Lixin (ed.). 2004. Contrastive Studies of Language and Culture between English and Chinese: 1995-2003. Shanghai: Shanghai Education Publishing House, pp.40-51.]

[26] Yuan, Hui \&Zong Yanhu. (1998). A History of Chinese Rhetoric. Taiyuan: Shanxi People’s Publishing House.

[27] Zhi Qian(Lokaksema). (230). "Preface to Dharma Pãda", Chos-skyabs (tr.), in CBETA, vol.4. p. 5b-c.

[28] Zhou Yi \& Luo, Ping. (1999). Translation and Translation Criticism. Wuhan: Hu Bei Education Press.

Hongwei Jia was born in Wuchang, Heilongiiang Province, China in 1977. He received his M.A. degree in linguistics from Heilongjiang University in 2005 and obtained his Ph.D in Linguistics from Beijing Foreign Studies University in 2011.

$\mathrm{He}$ is currently doing his postdoctoral research at Department of Chinese Minority Languages and Literature, Minzu University of 
China. He has published more than twenty academic papers on linguistics, translation studies, and sociolinguistics. He has also finished 2 projects. His academic interests cover general linguistics, sociolinguistics, history of modern Chinese linguistic thoughts, history of modern semantics and translation studies.

Jiafeng Tian was born in Wangdu, Hebei Province, China in 1981. He received his B.A. degree in logistic management from Beijing Jiaotong University in 2006

He is currently working as purchasing staff at Beijing Techwin Electric Co. Ltd. He has covered dozens of books and journal papers over logistics, human resource and management, sociolinguistics, applied electronics, and logic, and has registered for master program of MPA at Minzu University. His major academic interests cover history of Chinese linguistic thoughts, sociolinguistics, public administration and management. 